\title{
Tromboemboli profilaksisinde mekanik yöntemler
}

\author{
Mechanical methods in thromboembolism prophylaxis
}

\author{
Burak Beksaç \\ Beksaç Sağlık Hizmetleri, Ortopedi ve Travmatoloji, İstanbul
}

\begin{abstract}
Majör ortopedik cerrahi, venöz tromboemboli açısından yüksek riskli gruba girmektedir. Venöz tromboemboli, mortaliteye kadar gidebilen komplikasyonlara neden olabileceğinden, bu komplikasyonların önlenmesi için profilaksi şarttır. Venöz tromboemboli profilaksisi farmakolojik ve mekanik olarak birbirini tamamlayıcı iki bölüme ayrılabilir. Profilaksi için kullanılan mekanik metodlar arasında; ameliyat sonrası erken hasta mobilizasyonu, dereceli basınçlı çoraplar, intermittan pnömatik (alt ekstremiteye aralıklı basınç uygulayan) cihazlar ve venöz ayak pompaları vardır. Venöz tromboemboli profilaksisinde mekanik yöntemlerin kullanımı orta/düşük kanıt düzeyinde olsa da başlıca kılavuzlarda kuvvetli olarak tavsiye edilmektedir. Mümkünse tümünün (erken mobilizasyon, ayak bileği hareketleri, dereceli basınçlı çoraplar ve intermittan pnömatik cihazlar) farmakolojik profilaksiye ek olarak kullanımı, derin ven trombozu ve buna bağlı gelişebilecek pulmoner emboliyi azaltıcı etki gösterir.
\end{abstract}

Anahtar sözcükler: tromboemboli; profilaksi; mekanik
Major orthopaedic surgery is, by definition, a high risk procedure for venous thromboembolism. Since venous thromboembolism may cause complications that may lead to mortality which includes fatal pulmonary embolism, prophylaxis is mandatory to avoid/reduce these complications. Venous thromboembolism prophylaxis can be studied in two complementary sections: pharmacological and mechanical. Components of mechanical prophylaxis are: early post-operative mobilization, gradual compression stockings, intermittent pneumatic compression devices and venous foot pumps. The use of mechanical prophylaxis methods is strongly recommended in major guidelines, even though the evidence levels are medium to weak. If possible, the use of all of them (early mobilization, ankle movements, gradual compression stockings and intermittent pneumatic compression devices) in addition to pharmacological prophylaxis have the effect of reducing deep vein thrombosis and related pulmonary embolism.

Key words: thromboembolism; prophylaxis; mechanical
O rtopedik cerrahi, venöz tromboemboli (VTE) açısından, tanım olarak yüksek risk kategorisine girmektedir. ${ }^{[1]}$ VTE oluşumu; ameliyat öncesi hasta risk faktörleri, ameliyat sırasında uygulanan mekanik ve biyokimyasal etkiler ve ameliyat sonrası parametreler ile ilişkili, multifaktoriyel (çok nedenli) bir patolojidir ve elbette ki önlenmesi, bu nedenlere karşı alınacak multimodal (çok çeşitli) profilaksi ve tedavi ile mümkündür. ${ }^{[2]}$ Venöz tromboembolizmin nedeni, bacak derin venlerinde oluşan trombüslerdir. Bacak derin venlerini popliteal bifurkasyon düzeyinden proksimal ve distal olarak ayırırsak, pulmoner emboliye (PE) neden olma riski en yüksek olan trombüsler proksimalde yerleşenlerdir. Ortopedik cerrahi hastalarında PE, prevalansı düşük olsa da, mortaliteye gidebilecek bir neden olmasından dolayı ciddi bir risk parametresidir. Derin ven trombozu (DVT) ise daha sık görülür ve posttrombotik sendrom, kronik tromboembolik pulmoner hipertansiyon gibi tedavisi zor ve maliyetli tıbbi komplikasyonlar yaratabilir. Bu nedenle, VTE profilaksisi çok önem taşır. Bu makalede VTE profilaksisi için kullanılan mekanik yöntemler anlatılmaktadır.

VTE profilaksisi için kullanılan mekanik metodlar arasında; ameliyat sonrası erken hasta mobilizasyonu, dereceli basınçlı çoraplar (DBÇ), intermittan pnömatik (alt ekstremiteye aralıklı basınç uygulayan) cihazlar (IPBC) ve venöz ayak pompaları (VAP) vardır. Bu metodların tümü, konuyla ilgili en kapsamlı kılavuzlar olan, American Academy of Orthopaedic Surgeons (AAOS), American College of Chest Physicians

- Illetişim adresi: Prof. Dr. Burak Beksaç, Beksaç Sağlık Hizmetleri, Vişnezade Sok. Acısu Ap.16/3, Maçka 34357 İstanbul

Tel: 0212 - 2590029 e-posta: dr@burakbeksac.com

- Geliş tarihi: 11 Haziran 2019 Kabul tarihi: 6 Ağustos 2019 
(ACCP) ve Ingiltere National Institute for Health and Care Excellence (NICE) tromboprofilaksi kılavuzlarında farmakolojik profilaksiye ek olarak, yüksek tavsiye dereceleriyle yer almaktadır (Tablo 1 ). ${ }^{[3-5]}$

Mekanik VTE profilaksi metotlarının genel avantajları; kanama riski yaratmamaları, kan testleriyle monitörizasyon gerektirmemeleri ve klinik yan etki olasılıklarının düşük olmasıdır. ${ }^{[4]}$ Dezavantajları arasında ise; hasta konforunu azaltmaları, buna bağlı hasta uyumsuzluğu ve kanıt derece düzeylerinin orta/ düşük olması vardır. ${ }^{[5]}$ Ayrıca, mekanik VTE profilaksi cihazları, bacaklarında venöz yetmezlik yaraları, enfeksiyon, periferik arter hastalığı, kalp yetmezliği olan hastalarda kullanılamaz.

Erken hasta mobilizasyonu ve ayak bileğinin plantar/ dorsal pompa hareketi, muhtemelen en kolay uygulanabilen mekanik VTE profilaksi metodudur. ${ }^{[2]}$ Alt ekstermite venöz sistemde staz azaltılarak, oluşabilecek veya büyüyebilecek bir DVT önlenebilir. Bu metotların uygulanmamasının birincil nedeni, özellikle düşkün hastalarda kooperasyon sağlanamamasıdır. Erken mobilizasyonun, total kalça protezi hastalarında semptomatik VTE'yi, hastanede yatış süresini, genel komplikasyon oranını ve ameliyat sonrası ilk altı ay mortalite oranını azalttığı kanıtlanmıştır. ${ }^{[6]}$

DBÇ, ameliyat sırasında karşı ekstremitede, ameliyat sonrasında ise her iki alt ekstremitede kullanılabilir. Diz altına kadar, kasığa kadar uzun ve külotlu çorap tarzında olanları vardır. Total protez ve kalça kırı̆̆ı hastalarının çoğunun yaşının ileri olduğu ve vücut/bacak yapıları göz önüne alınarak, bu çorapların boyutlarının çok iyi seçilmesi gerekir. Gevşek çorap herhangi bir yarar sağlamayacakken, çok sıkı bir çorap dolaşımı ve doku oksijenizasyonunu bozabilir. ${ }^{[7]}$ Eğer iyi uygulanmaz ve/veya takip edilmez ise, uylukta ve diz arkasında kıvrılarak, venöz turnike etkisi ya da kesik tarzı yaralara neden olabilir. Hastanın bacak yapısı ve uyumu değerlendirilerek uzun veya diz altı DBÇ seçilmeli, hasta ve yakınlarına takip için eğitim verilmelidir. Duş için ve gün içinde 1-2 saat çıkartılarak kullanımı hasta uyumunu arttırabilir. Ameliyat sonrası en az üç, mümkünse bacak şişliği kalmayana kadar, altı hafta kullanımı tavsiye edilmektedir.

IPBC, alt ekstermiteyi distalden proksimale sıkıştırarak dolaşımı desteklemek ve stazı önlemek amacıyla kullanılır. Diz altı, dizüstü ve sadece ayak tabanını sıkıştıran (VAP) tipleri vardır. IPBC'lerin, VTE profilaksisindeki etkinliği, özellikle plazminojen aktivatör inhibitör-1 düzeylerini azaltarak fibrinolitik aktiviteyi arttırdığı gösterilmiştir. ${ }^{[8]} \mathrm{Bu}$, farmakolojik antikoagülan tedaviye ciddi bir destek vererek, dozun düşük tutulabilmesine olanak sağlar. En önemli dezavantajları; etkili olabilmesi için sürekli olarak çalışması gerekliliği, buna bağlı hastanın hareketliliğini azaltıcı etkisi, özellikle gece uykuyu engelleyebilmesidir. Hastanın hareketliliğini azaltmamak ve uyumu arttırmak adına, taşınabilir, pille çalışan modeller üretilmiş ve kullanılmaktadır. ${ }^{[9]}$

Tablo 1. AAOS, ACCP ve NICE kılavuzlarındaki mekanik profilaksi önerileri ve tavsiye dereceleri

\begin{tabular}{|c|c|}
\hline Kılavuz ismi & Mekanik profilaksi tavsiyesi ve derecesi \\
\hline AAOS & $\begin{array}{l}\text { - Elektif kalça veya diz artroplastisi uygulanan ve VTE veya kanama açııından ameliyatın getirdiğinden yüksek risk } \\
\text { taşımayan hastalarda VTE profilaksisi için farmakolojik ve/veya mekanik kompresyon cihazları kullanılmasını } \\
\text { öneriyoruz. } \\
\text { - Orta derece } \\
\text { - Elektif kalça veya diz artroplastisi geçiren ve önceden venöz tromboembolizm gelişmiş olan hastalarda farmakolojik } \\
\text { profilaksi ve mekanik kompresyon cihazları kullanılmasını önermekteyiz. } \\
\text { - Fikir Birliği } \\
\text { - Elektif kalça veya diz artroplastisi geçiren ve bilinen kanama bozukluğu (örn.; hemofili) ve/veya aktif karaciğer hastalığı } \\
\text { olan hastalarda VTE profilaksisi amacıyla mekanik kompresyon cihazları kullanılmasını önermekteyiz. } \\
\text { - Fikir Birliği } \\
\text { - Elektif kalça veya diz artroplastisi sonrasında hastalarda erken mobilizasyon sağlanması gerektiği yönündedir. } \\
\text { - Fikir Birliği }\end{array}$ \\
\hline ACCP & $\begin{array}{l}\text { - Elektif kalça/diz artroplastisi ve kalça kırığı cerrahisi sonrasında mekanik kompresyon cihazları kullanımını } \\
\text { önermekteyiz. } \\
\text { - 1C Kuvvetli tavsiye, düşük kanıt düzeyi }\end{array}$ \\
\hline NICE & $\begin{array}{l}\text { - Elektif kalça veya diz artroplastisi ve kalça kırı̆ı̆ cerrahisi uygulanacak hastalara, yatıştan itibaren, mekanik ve } \\
\text { farmakolojik yöntemler kombine edilerek VTE profilaksisi uygulanmalıdır. Hastada yeterli mobilizasyon sağlanana } \\
\text { kadar mekanik yöntemlerle (DBÇ, IPBC, VAP) VTE profilaksisine devam edilmelidir. }\end{array}$ \\
\hline
\end{tabular}

AAOS, American Academy of Orthopaedic Surgeons; ACCP, American College of Chest Physicians; NICE, National Institute for Health and Care Excellence. 
Doğru kullanıldığında, IPBC’lerin etkili olduğu birçok çalışmada gösterilmiştir. ${ }^{[8]}$

Sonuç olarak, VTE profilaksisinde mekanik yöntemlerin kullanımı orta/düşük kanıt düzeyinde olsa da kuvvetli olarak tavsiye edilmektedir. Mümkünse tümünün (erken mobilizasyon, ayak bileği hareketleri, DBÇ ve IPBC) farmakolojik profilaksiye ek olarak kullanımı, DVT ve buna bağlı gelişebilecek pulmoner emboliyi azaltıcı etki göstermektedir. Kullanım zorlukları, hemşire, ek personel, hasta ve yakınlarının eğitimi ve yardımıyla kullanımı en uygun ve kolay hale getirilebilir.

\section{KAYNAKLAR}

1. Geerts WH, Pineo GF, Heit JA, Bergqvist D, Lassen MR, Colwell CW, Ray JG. Prevention of venous thromboembolism: the Seventh ACCP Conference on Antithrombotic and Thrombolytic Therapy. Chest 2004;126(3 Suppl):338S400S. Crossref

2. Salvati EA, Sharrock NE, Westrich G, Potter HG, Della Valle AG, Sculco TP. The 2007 ABJS Nicolas Andry Award: three decades of clinical, basic, and applied research on thromboembolic disease after THA; rationale and clinical results of a multimodal prophylaxis protocol. Clin Orthop Relat Res 2007;459:246-54. Crossref

3. American Academy of Orthopaedic Surgeons. Preventing venous thromboembolic disease in patients undergoing elective hip and knee arthroplasty. Evidence-based guidelines and evidence report, 2nd ed. Rosemont, IL, USA: AAOS; 2011. Erişim: http://www.aaos.org/research/guidelines/ VTE/VTE_full_guideline.pdf
4. Falck-Ytter Y, Francis CW, Johanson NA, Dahl OE, Schulman S, Ortel TL, Pauker SG, Colwell CW. Prevention of VTE in Orthopedic Surgery Patients. Antithrombotic Therapy and Prevention of Thrombosis, 9th ed: American College of Chest Physicians Evidence-Based Clinical Practice Guidelines. Chest 2012;141(2 Suppl):e278S-325S. Crossref

5. Afshari A, Fenger-Eriksen C, Monreal M, Verhamme $P$; ESA VTE Guidelines Task Force. European guidelines on perioperative VTE prophylaxis: Mechanical prophylaxis. Eur J Anaesthesiol 2018;35(2):112-5. Crossref

6. Hoenig $\mathrm{H}$, Rubenstein LV, Sloane R, Horner R, Kahn K. What is the role of timing in the surgical and rehabilitative care of community-dwelling older persons with acute hip fracture? Arch Intern Med 1997;157(5):513-20. Crossref

7. Agu O, Hamilton G, Baker D. Graduated compression stockings in the prevention of venous thromboembolism. Br J Surg 1999;86(8):992-1004. Crossref

8. Pavon JM, Adam SS, Razouki ZA, McDuffie JR, Lachiewicz PF, Kosinski AS, Beadles CA, Ortel TL, Nagi A, Williams JW. Effectiveness of Intermittent Pneumatic Compression Devices for Venous Thromboembolism Prophylaxis in HighRisk Surgical Patients: A Systematic Review. J Arthroplasty 2016;31(2):524-32. Crossref

9. Berliner JL, Ortiz PA, Lee YY, Miller TT, Westrich GH. Venous Hemodynamics After Total Hip Arthroplasty: A Comparison Between Portable vs Stationary Pneumatic Compression Devices and the Effect of Body Position. J Arthroplasty 2018;33(1):162-6. Crossref 